\title{
Places Mentioned in Lucio V. Mansilla's Narrative and Expedition and Surveying Routes
}

(After the map in the 1947 Fondo de Cultura Económica edition of Una excursión a los indios ranqueles.)

\author{
I. Río Cuarto \\ 2. Río Saladillo \\ 3. La Carlota \\ 4. Chaján \\ 5. Cuadril \\ 6. Tres de Febrero \\ 7. Paso del Lechuzo \\ 8. Fort General Arredondo \\ 9. Laguna de Langhelo \\ I0. Tres Lagunas \\ I I. Antiguo Melincué \\ I 2. Fort Chañares \\ 13. Melincué \\ I4. Melincué Viejo \\ I 5. Laguna Alegre \\ I6. Monte de la Vieja
}

I7. Zorro Colgado

I8. Pollo-helo

19. Us-helo

20. Tremencó

2r. Laguna del Cuero

22. Pozos de Bayo-manco

23. Lonco-uaca

24. Chamalcó

25. Utatriquin

26. Agustinillo

27. Laguna Bagual

28. Aillancó

29. Leubucó (Mariano Rosas)

30. Patamu

3I. Quenqué (Baigorrita)

32. Río Quinto 
THIS PAGE INTENTIONALLY LEFT BLANK 